\section{EXPERT OPINION}

1. Introduction

2. Biochemistry

3. Pharmacokinetic properties

4. Pharmacodynamic profile

5. Neuroplasticity

6. Preclinical studies of fluoxetine

7. A reflection on the first clinical studies validating the antidepressant effects of fluoxetine

8. Conclusion

9. Expert opinion

\title{
Fluoxetine: a case history of its discovery and preclinical development
}

\author{
Laura Perez-Caballero, Sonia Torres-Sanchez, Lidia Bravo, \\ Juan Antonio Mico \& Esther Berrocoso ${ }^{\dagger}$ \\ ${ }^{\dagger}$ University of Cadiz, Department of Psychology, Neuropsychopharmacology and Psychobiology \\ Research Group, Psychobiology Area, Cadiz, Spain
}

Introduction: Depression is a multifactorial mood disorder with a high prevalence worldwide. Until now, treatments for depression have focused on the inhibition of monoaminergic reuptake sites, which augment the bioavailability of monoamines in the CNS. Advances in drug discovery have widened the therapeutic options with the synthesis of so-called selective serotonin reuptake inhibitors (SSRIs), such as fluoxetine.

Areas covered: The aim of this case history is to describe and discuss the pharmacokinetic and pharmacodynamic profiles of fluoxetine, including its acute effects and the adaptive changes induced after long-term treatment. Furthermore, the authors review the effect of fluoxetine on neuroplasticity and adult neurogenesis. In addition, the article summarises the preclinical behavioural data available on fluoxetine's effects on depressive-like behaviour, anxiety and cognition as well as its effects on other diseases. Finally, the article describes the seminal studies validating the antidepressant effects of fluoxetine.

Expert opinion: Fluoxetine is the first selective SSRI that has a recognised clinical efficacy and safety profile. Since its discovery, other molecules that mimic its mechanism of action have been developed, commencing a new age in the treatment of depression. Fluoxetine has also demonstrated utility in the treatment of other disorders for which its prescription has now been approved.

Keywords: antidepressant, depression, fluoxetine, selective serotonin reuptake inhibitor, serotonin

Expert Opin. Drug Discov. [Early Online]

\section{Introduction}

Major depression disorder (MDD) is a mental disorder that affects $>350$ million people of all ages, with the highest proportion of cases occurring between 25 and 34 years of age. According to the World Health Organization, depression is projected to become the second leading contributor to the global burden of disease by the year 2020 [1]. MDD is diagnosed according to the symptoms described in the Diagnostic Manual and Statistical of Mental Disorders, and the first-line therapy for depression involves the use of antidepressants that principally act by inhibiting monoamine reuptake. In this review, we describe the discovery, assays, development and some aspects of the clinical use of fluoxetine. This compound has for decades been the most commonly prescribed selective serotonin reuptake inhibitor (SSRI). It was launched for the treatment of depression at the end of the 1980s, and its clinical used has since been expanded to other disorders. Moreover, other compounds with a similar mechanism of action have also been developed and introduced into clinical practice. 


\section{Article highlights.}

- Fluoxetine is a selective serotonin reuptake inhibitor that increases the concentration of 5-hydroxytryptamine (5-HT) in many brain areas without affecting other neurotransmitter receptors.

- Fluoxetine and its active metabolite norfluoxetine have a long half-life, which is considered to be advantageous, given that it minimises withdrawal.

- Chronic fluoxetine treatment induces adaptive changes in serotoninergic systems, such as the desensitisation of 5-HT autoreceptors.

- Fluoxetine can enhance neuroplasticity and augment adult neurogenesis.

- In general, preclinical behavioural studies show that chronic but not acute fluoxetine administration improves depressive-like behaviour, anxiety and cognition.

- Clinical trials have validated the antidepressant efficacy and safety of fluoxetine to treat depression, and its use for other pathologies has been approved.

- Fluoxetine inhibits the CYP isozymes and might potentiate drug interactions.

This box summarises key points contained in the article.

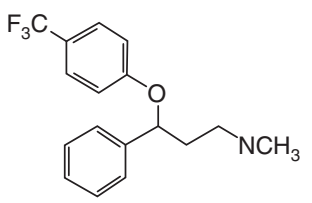

Figure 1. Chemical structure of fluoxetine (LY110140).

In the early twentieth century, depression was identified as 'melancholia', and it was mainly treated with barbiturates and amphetamines. It was not until the 1950s when the first two compounds with more potent antidepressant activity were developed, named antidepressants. They are iproniazid, the first monoamine oxidase inhibitor (MAOI), and imipramine, the first tricyclic antidepressant (TCA). The emergence of these two antidepressant drugs revolutionised psychiatry and the pharmaceutical industry. Indeed, the discovery of these new treatments for MDD led to the development of new theories about the pathophysiology of the mood disorder. Ten years later, other TCAs were synthesised (amitriptyline, nortriptyline, desipramine and clomipramine), some of which are still in use to treat depression and other pathologies. By contrast, the intolerance and side effects observed in patients treated with MAOIs (nephrotoxicity and hypertension) limited the prescription of MAOIs and there is a strong decline in their use.

In 1965, the monoaminergic hypothesis of depression was postulated [2], which implicated noradrenergic and serotoninergic dysfunction in depression. As a result, some pharmaceutical companies focused their research on the search for new drugs that specifically target 5-HT reuptake. Thus, an SSRI was developed by Eli Lilly and Company, the compound numbered LY110140 (fluoxetine) was initially approved as a drug for medical use in Belgium in 1986, although it was not approved by the FDA until 1987, under the name of Prozac $^{\circledR}$. Numerous clinical trials reported that the antidepressant efficacy of fluoxetine was as potent as the TCA but with fewer side effects due to its selective profile [3]. However, some adverse effects are associated with fluoxetine, which could limit the treatment adherence, and not all patients reached the desired therapeutic response after fluoxetine treatment. However, this antidepressant drug was a breakthrough in the treatment of depression, being prescribed since the 1980s; indeed its clinical use has been extended even to other pathologies.

Finally, it must be taken into account that fluoxetine treatment has a delayed onset of therapeutic action requiring several weeks to achieve a sustained increase in monoamine levels, which produces adaptive changes and the subsequent antidepressant effect. According to the monoaminergic hypothesis, an acute monoamine increase should produce an immediate antidepressant response but sadly this does not happen. This fact calls into question this hypothesis of depression, leading to propose other underlying mechanisms that might explain the antidepressant effect of fluoxetine such as neurotrophic factors and other novel target molecules cited in the present review.

\section{Biochemistry}

Fluoxetine (Lilly 110140: 3-(p-trifluoromethylphenoxy)- $N$ methyl-3-phenylpropylamine) is an SSRI (Figure 1) that exists as a racemic molecule, with the $\mathrm{R}(-)$ and $S(+)$ enantiomers showing equal potency as inhibitors of 5-hydroxytryptamine (5-HT) uptake in both in vitro and in vivo uptake assays [4]. Moreover, fluoxetine is metabolised by $N$-demethylation to norfluoxetine, which is an active metabolite. Norfluoxetine also acts as an SSRI but with a stronger potency than the parental compound [5]. This active metabolite also exists in an enantiomeric form, but unlike fluoxetine enantiomers, $S$-norfluoxetine is over 20 -fold more potent in inhibiting 5-HT uptake than the $(R)$-enantiomer [6].

\section{Pharmacokinetic properties}

The pharmacokinetic parameters of fluoxetine reveal it to be efficiently absorbed from the rat gastrointestinal tract after oral administration. Due to hepatic first-pass metabolism, the oral bioavailability is $<90 \%$ [7]. Fluoxetine has a high lipophilic profile, and it appears to bind strongly to plasma protein, which means it is widely distributed. Thus, high concentrations of fluoxetine and its metabolite norfluoxetine reach the brain. Early studies with fluoxetine in humans using radioactive isotopes showed that about $75 \%$ of the radioactivity was excreted in the urine and $10 \%$ was recovered in the faeces over the following 30 days. Fluoxetine is converted metabolically to norfluoxetine and other metabolites (Figure 2) [8], and CYP 


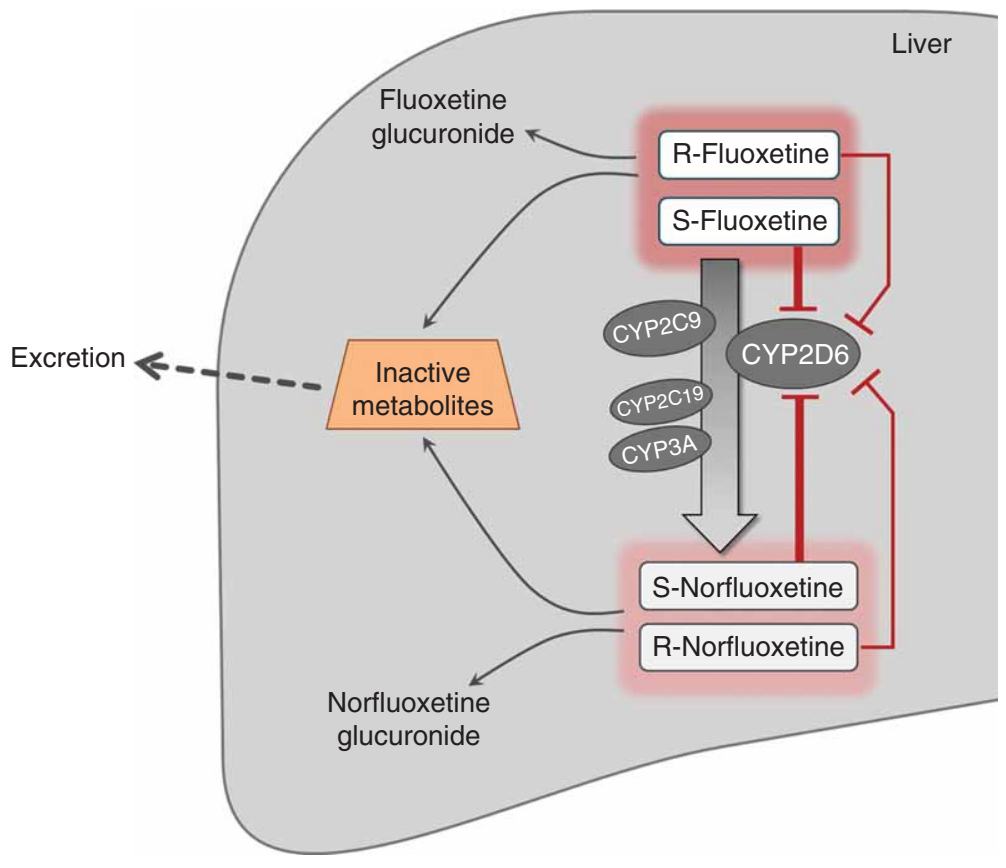

Figure 2. Schematic representation of fluoxetine metabolism pathway.

isozymes play an essential role in the clearance of both fluoxetine and norfluoxetine. Furthermore, both compounds inhibited CYP2D6 isozymes in vitro and in vivo. The $(S)$-enantiomers of fluoxetine and norfluoxetine are six times more potent than both $(R)$-enantiomers (Figure 2) [9], and therefore, both compounds can compete with other drugs for their metabolism by CYP2D6, which would explain their potential to participate in pharmacokinetic drug interactions [9].

In addition, fluoxetine and norfluoxetine have a long half-life, and the half-life of the active metabolite is being longer. Indeed, the plasma elimination half-life in humans was 1 - 3 for fluoxetine and 7 - 15 days for norfluoxetine [10]. This long half-life could be considered as an advantage for fluoxetine because it avoids the induction of withdrawal syndrome when it is necessary to suppress or change the medication. By contrast, it must be kept in mind that fluoxetine inhibits CYP2D6 and potentiates drug interactions.

\section{Pharmacodynamic profile}

\subsection{Inhibition of monoamine uptake}

The first in vitro study of fluoxetine kinetics showed that this compound selectivity inhibited 5-HT uptake into synaptosomes isolated from whole rat brain with a $\mathrm{Ki}$ of $5.2 \times 10^{-8}$ $\mathrm{M}$, whereas the inhibition constant for the blockade of noradrenaline uptake was $1 \times 10^{-5} \mathrm{M}$ and that for dopamine uptake was $1.5 \times 10^{-5} \mathrm{M}$ [11]. Subsequent in vitro uptake studies confirmed the strong capacity of fluoxetine to inhibit 5-HT uptake, greater than its affinity for other monoamines (Table 1) $[12,13]$.
In vivo uptake studies into rat brain synaptosomes also demonstrated that acute fluoxetine administration produced a significant reduction in 5-HT uptake (57\%) compared with controls but not that of noradrenaline or dopamine $[11,13]$. The brain regions with the most pronounced reduction in 5-HT uptake were the cerebral cortex and brainstem, whereas fluoxetine administration failed to inhibit uptake into synaptosomes in cerebellum [13]. In vivo studies were carried out to evaluate the duration of the effects of fluoxetine on 5-HT uptake inhibition, demonstrating that maximal inhibition occurred after $4 \mathrm{~h}$ and that uptake was restored to normal levels $48 \mathrm{~h}$ after administration of fluoxetine. However, throughout this time course, the uptake of noradrenaline was unaltered by fluoxetine administration [13]. The effect of fluoxetine was long lasting compared with the time course of other antidepressants, which could reflect the extremely long half-life of both fluoxetine and its active metabolite, norfluoxetine [14]. Overall, these data suggest that the metabolite plays an important role for the therapeutic effect of fluoxetine.

\subsection{Transporters and receptors binding}

Several competitive binding assays with monoamine transporters showed that fluoxetine presents a strong affinity for the 5-HT transporter and only a weak or no affinity for the noradrenaline and dopamine transporters, respectively [12,15,16]. Therefore, these data confirmed the 5-HT selective profile of this compound. Furthermore, fluoxetine showed relatively weak affinity for 5-HT receptors, as measured by radioligand binding to the $5-\mathrm{HT}_{1}(\mathrm{~A}, \mathrm{~B}, \mathrm{C}$ and $\mathrm{D}), 5-\mathrm{HT}_{2}$ and $5-\mathrm{HT}_{3}$ 
Table 1. In vitro binding affinities of fluoxetine for the inhibition of catecholamine uptake and for serotonin, noradrenaline and dopamine transporters.

Binding affinity and $\quad$ Ki (M)
inhibition uptake

[ $\left.{ }^{3} \mathrm{H}\right]-5-\mathrm{HT}$ uptake synaptosomes $5.2 \times 10^{-8}$ rat brain [11]

$\left[{ }^{3} \mathrm{H}\right]$-Noradrenaline uptake synaptosomes rat brain [11] $\left[{ }^{3} \mathrm{H}\right]$-Dopamine uptake synaptosomes rat brain [11] $\left[{ }^{3} \mathrm{H}\right]$-Citalopram in vitro binding rat cortex [12]

$\left[{ }^{3} \mathrm{H}\right]$-Nisoxetine in vitro binding rat cortex [12]

$\left[{ }^{3} \mathrm{H}\right]$-Citalopram in vitro binding human transfected cells [12] $\left[{ }^{3} \mathrm{H}\right]$-Nisoxetine in vitro binding human transfected cells [12]

5-HT: 5-Hydroxytryptamine; Ki: Mean of affinity constants expressed in $M \pm$ S.E.M. (standard error of the mean).

Table 2. Fluoxetine affinities for various neurotransmitter receptors.

\begin{tabular}{ll}
\hline Receptors affinity & IC $_{\mathbf{5 0}}$ (nM) \\
\hline $5-\mathrm{HT}_{1 \mathrm{~A}}$ & 79,000 \\
$5-\mathrm{HT}_{2 \mathrm{~A}}$ & 710 \\
$5-\mathrm{HT}_{2 C}$ & 160 \\
Dopamine D1 & 10,000 \\
Dopamine D2 & 32,000 \\
$\alpha_{1}$-adrenergic & 14,000 \\
$\alpha_{2}$-adrenergic & 2800 \\
$\beta$-adrenergic & 18,000 \\
Cholinergic muscarinic & 3100 \\
Histamine H1 & 3200
\end{tabular}

5-HT: 5-Hydroxytryptamine.

subtypes, although the strongest affinity was found for $5-\mathrm{HT}_{2}$ receptors $[5,12,17]$. Additional studies were carried out to evaluate the interaction of fluoxetine with other neurotransmitters receptors, with radioligand-binding assays showing that fluoxetine has low affinity for $D_{1}$ and $D_{2}$ dopaminergic, $\alpha$ - and $\beta$-adrenergic, muscarinic cholinergic and histamine $\mathrm{H}_{1}$ receptors (Table 2) [5,12]. On the contrary, TCA present a greater affinity for several neurotransmitters receptors, which conferred them a side-effect profile, worsening the antidepressant therapy. Thus, their affinity for muscarinic cholinergic receptors may induce blurred vision, dry mouth, constipation, urinary retention, seizures or memory impairment; histaminergic receptor antagonism can produce sedation or drowsiness and the blockade of $\alpha_{1}$-adrenergic receptors is associated with cardiotoxicity effects, including tachycardia, orthostatic hypotension and dizziness. Overall, these findings are consistent with the lack of fluoxetine's side effects, which were often observed with TCA drugs. However, fluoxetine also has adverse effects, affecting the patient compliance and treatment adherence. Thereby, fluoxetine often causes nausea, diarrhoea, loss of appetite and sexual dysfunction. Additionally, it could be accompanied by other negative effects such as insomnia, anxiety or even may induce the so-called 'serotonin syndrome', characterised by specific symptoms including agitation, mental confusion, hyperthermia, arrhythmia, diarrhoea and tremor.

\subsection{Acute fluoxetine}

Microdialysis studies revealed that acute fluoxetine administration enhances extracellular 5-HT levels, in conjunction with a decrease in both the synthesis and turnover of 5-HT in the raphe nuclei [18]. An increase in 5-HT has also been reported in other brain regions, such as the frontal cortex, striatum, diencephalon or hippocampus [18-21]. In particular, it should be note that the 5-HT increase in the frontal cortex by acute fluoxetine treatment is smaller than that in the raphe nuclei $[22,23]$. This could reflect the activation of somatodendritic $5-\mathrm{HT}_{1 \mathrm{~A}}$ autoreceptors provoked by the large increase in 5-HT in the raphe nuclei, which may negatively control cell firing and 5-HT release into terminal areas including the frontal cortex [24,25]. This issue arose in microdialysis and electrophysiological studies with $5-\mathrm{HT}_{1 \mathrm{~A}}$ antagonists.

Unlike other SSRI, fluoxetine also increases dopamine and noradrenaline concentrations in the prefrontal cortex, as measured by microdialysis $[15,17]$. It was suggested that this effect might reflect an interaction with the $5-\mathrm{HT}_{2 \mathrm{C}}$ receptor, and indeed, it has been demonstrated that fluoxetine acts as a $5-\mathrm{HT}_{2 \mathrm{C}}$ receptor antagonist due to its relative affinity for this receptor [26]. This receptor subtype exerts inhibitory control on both ventral tegmental dopaminergic and locus coeruleus noradrenergic neurons [27]. Thus, the ability of fluoxetine to block $5-\mathrm{HT}_{2 \mathrm{C}}$ receptor is the most plausible explanation for the cortical increase in catecholamines. Other microdialysis studies indicated that fluoxetine increases noradrenaline and dopamine in the hypothalamus and ventral tegmental area, respectively [28,29], whereas it does not change the extracellular levels of these transmitters in brain areas such as the striatum or nucleus accumbens [30,31].

\subsection{Long-term fluoxetine}

Chronic fluoxetine treatment induces a persistent increase in 5-HT levels in several brain regions, such as the diencephalon, striatum, hippocampus and frontal cortex $[19,32,33]$, without altering those of cortical noradrenaline and dopamine [34,35]. Initially, it was suggested that sustained 5-HT enhancement was caused by the simple accumulation of higher plasma levels of fluoxetine or its metabolite, because they have a long half-life. However, this would appear to be unlikely given that residual drug was still present and the enhanced extracellular 5-HT levels were promptly restored after acute treatment [19,32]. Thus, several adaptive mechanisms associated with 5-HT neurotransmission have been 
proposed to explain the persistent changes of extracellular 5-HT after chronic fluoxetine treatment. Microdialysis and electrophysiology studies support the desensitisation of raphe somatodendritic 5 - $\mathrm{HT}_{1 \mathrm{~A}}$ autoreceptors $[19,33,36]$ that negatively regulate the release of 5-HT in terminal areas [37]. Through radioligand-binding assay and autoradiographic quantification, it was revealed that the ability of fluoxetine to downregulate the density of these autoreceptors might explain this altered sensitivity, although this hypothesis remains somewhat controversial [36,38-40]. However, it has also been suggested that the desensitisation of $5-\mathrm{HT}_{1 \mathrm{~A}}$ autoreceptors may be due to alterations in their signal transduction, which involves G-protein $[39,41]$.

Furthermore, there is evidence that the persistent increase in extracellular 5-HT induced by chronic fluoxetine might be explained by the desensitisation of terminal $5-\mathrm{HT}_{1 \mathrm{~B}}$ autoreceptors, whose activation exerts a feedback inhibition of 5-HT release, as demonstrated by electrophysiology and microdialysis assays $[42,43]$. Accordingly, the support for fluoxetine-induced $5-\mathrm{HT}_{1 \mathrm{~B}}$ subsensitivity came from the decrease in receptor expression observed [44], although other reports did not confirm this effect $[36,45]$. Other explanations of the mechanism of action of fluoxetine after long-term treatment have also been proposed. For example, the role of other 5-HT receptors has been evoked, given that chronic fluoxetine treatment also downregulates the density of $5-\mathrm{HT}_{4}$ receptors and produces a functional desensitisation involving the adenylate cyclase system [46]. By contrast, long-term treatment does not provoke robust alterations in other $5-\mathrm{HT}$ receptors, such as $5-\mathrm{HT}_{2}$ or $5-\mathrm{HT}_{3}$ $[45,47,48]$. In addition, there is some controversy regarding the role of 5-HT transporters in the adaptive changes following chronic fluoxetine administration $[36,38,44]$.

Chronic fluoxetine administration did not produce adaptive changes or downregulation of other neurotransmitter receptors (opioids, adrenergic, muscarinic or histamine H1 receptors) [40,47,48]. This favours possible advantages in the long-term treatment with fluoxetine because this compound will be less cardiotoxic than TCAs, with fewer anticholinergic and antihistaminergic side effects $[11,13,40]$. As the adaptive changes described above must be produced, it is widely accepted that chronic fluoxetine treatment is necessary to obtain a therapeutic effect. In this way, preclinical data suggest that can be used strategies based on fluoxetine treatment in combination with antagonists of the 5-HT desensitised receptors after long-term treatment to accelerate the clinical action of fluoxetine and even to improve its antidepressant efficacy $[22,43,46,49]$.

On the other hand, novel mechanisms of action have been proposed to elucidate the underlying bases of the antidepressant effect of fluoxetine. Recently, it has been described that fluoxetine induces epigenetic modifications that may contribute to the therapeutic action of this antidepressant. In this way, modifications in levels of acetylated histones [50] as well as altering the expression of some microRNAs (miRNAs) in several brain areas [51,52] have been related to depressive pathology. Thus, chronic fluoxetine treatment is able to reverse some of these changes and interestingly, these miRNAs alterations are also reversed by the nonpharmacological electroconvulsive therapy [52]. Even more, other new mechanisms have been proposed for this antidepressant, for example a recent study involves a chromatinremodelling factor in the antidepressant effect of fluoxetine [53]. Overall, the mechanism of action of this compound could open an avenue for understanding. However, further research is required to explain whether these epigenetic changes are directly related to the antidepressant effect of fluoxetine.

\section{Neuroplasticity}

\subsection{Neurotrophins and synaptic plasticity}

Neurotrophins are growth factors that critically regulate the formation and plasticity of neuronal networks. The neurotrophic hypothesis of depression postulates that a reduction in the neurotrophin brain-derived neurotrophic factor (BDNF) levels in the brain predisposes an individual to depression, whereas antidepressant activity induces an increase in BDNF [54].

Given the antidepressant effect of fluoxetine, several neurotrophic factors have been evaluated after single and chronic administrations of this compound. Accordingly, fluoxetine has been shown to have a 'biphasic' effect on BDNF transcription, first inducing its downregulation $4 \mathrm{~h}$ after acute or chronic treatment and subsequently provoking an increase at $24 \mathrm{~h}$, only after long-term treatment $[55,56$. Along similar lines, both acute and chronic fluoxetine treatments enhance the phosphorylation of the BDNF receptor, tropomyosin related kinase B (TrkB), suggesting an increase in BDNF release that may lead to a decrease in its transcription [57]. In addition, chronic fluoxetine administration also increases the cAMP-related element binding protein in the hippocampus, a major transcription factor directing gene expression of plasticity-related molecules, such as BDNF or TrkB receptor [58,59]. Although the most common neurotrophic factor that has been studied is BDNF, other neurotrophic factors have also been evaluated. For example, there is evidence of an increase in the vascular endothelial growth factor and basic fibroblast growth factor 2 in hippocampal neurons after chronic but not acute fluoxetine treatment $[60,61]$, which may maintain a close relationship with neuroplasticity and cellular adaptation. It is noteworthy that fluoxetine also increases synaptic plasticity, which might improve the reorganisation of neuronal circuits and induce a clinically beneficial effect $[62,63]$.

\subsection{Adult neurogenesis}

Several lines of evidence indicate that neurotrophic factors are closely linked to adult neurogenesis and plasticity, processes that are impaired during the course of depression. Indeed, it has been demonstrated that antidepressants have the capacity to regulate new cell birth and survival [64]. Accordingly, chronic fluoxetine treatment enhanced neurogenesis in the hippocampal subgranular zone and it has also been shown 
to increase cell proliferation and the long-term survival of the newborn granule neurons $[57,59,61,64]$.

\section{Preclinical studies of fluoxetine}

Due to the effect of fluoxetine on serotoninergic neurotransmission, many preclinical studies have demonstrated its antidepressant effect in several animal model of depression, including pharmacological models (reserpine), the forced swimming test (FST), chronic mild stress (CMS), learned helplessness (LH), olfactory bulbectomy (OB), as well as assessing its effect on anxiety, cognition and others processes. In general, the inhibition of 5-HT reuptake mediated by fluoxetine reduces food intake and consequently body weight [65], foot-shock induced aggression [66], sexual behaviour [67] and it produces potent antidepressant effects that are described in more detail below.

\subsection{Effect on depressive-like behaviour}

The antidepressant activity of fluoxetine as an SSRI is well established, and furthermore, it is currently being used to validate animal models of depression [68]. Nevertheless, it is important to note that there are some predictive models of depression that do not respond to SSRI, at least, following acute administration.

Early pharmacological studies regarding the antidepressant effect of fluoxetine showed a potentiation of the 5-hydroxytryptophan-induced suppression of operant response [69], probably due to its 5-HT selective profile. By contrast, fluoxetine was ineffective in reversing hypothermia in the pharmacological model of reserpine [70]. In 1995, studies using animal models of depression (such as LH) showed that chronic administration of fluoxetine significantly prevented the behavioural escape deficits produced by the repeated exposition to unpredictable shocks [71].

Conversely, the antidepressant activity of fluoxetine has been demonstrated widely in the FST, a test of antidepressant activity where immobility represents 'behavioural despair', a classical depressive-like behaviour. Studies using the FST suggest that increased serotoninergic neurotransmission is involved with enhanced swimming behaviour and not only does fluoxetine enhance swimming behaviour, as an SSRI it also decreases the immobility time [72]. These effects in the FST have been observed after both acute- (three times $24 \mathrm{~h}$ prior to test) and chronic-term (over 14 - 21 days) administrations but not after subchronic (3 days) treatment. Moreover, these effects on immobility and swimming behaviour were mainly observed in Sprague-Dawley rats and BALB/c mice [73,74]. By contrast, Wistar Kyoto rats, and C57BL/6 and $129 \mathrm{SvEv}$ mice, are resistant to the effects of fluoxetine in the FST paradigm [74,75]. Thus, the antidepressant effect of fluoxetine in the FST seems to be strain-dependent, probably due to the genetic background of each strain. Hence, identifying the genes associated with resistance to fluoxetine treatment will be interesting to understand the pathophysiology of depression.
Disturbances in the rapid eye movement (REM) phase of sleep are characteristic of depressive patients, and it has been demonstrated that chronic administration of fluoxetine can improve this defect [76]. Interestingly, similar findings were obtained in preclinical research, where both acute [77] and chronic administrations of fluoxetine were effective in decreasing REM sleep in rodents [78].

The antidepressant efficacy of fluoxetine has been also tested in CMS. CMS-induced depressive-like behaviour has been seen to be reversed by chronic treatment with fluoxetine. Indeed, anhedonia, a core symptom of MDD, was reversed after long-term fluoxetine treatment in chronically stressed rats [79]. Moreover, secondary effects associated with the CMS model, such as cardiovascular impairments, were also reversed by chronic administration with fluoxetine [79], suggesting that the treatment of MDD with this antidepressant could be appropriate in cardiac depressed patients.

Additionally, fluoxetine has been used in other animal models of depression, including that involving the bilateral lesion of the olfactory bulb. OB has been characterised as inducing behavioural and neurochemical changes related to clinical depression, such as motor agitation, cognitive impairment, noradrenergic and serotoninergic dysfunctions [80]. Interestingly, it has been demonstrated that OB-induced depressive behaviour is reversed after chronic fluoxetine administration [81]. Furthermore, it was demonstrated that fluoxetine normalised OB-induced hyperactivity and that it reversed the physiological parameters associated with this model of depression, such as the altered heart rate and body temperature [82].

\subsection{Effect on anxiety-like behaviour}

As increases in 5-HT have been associated with anxiety, the effect of fluoxetine on this phenomenon has been studied. Most studies into anxiety have demonstrated that acute administration of fluoxetine provokes an anxiogenic-like effect in the elevated plus maze [83,84], a clinical effect typical of the first-phase of fluoxetine treatment. However, studies on chronic administration of fluoxetine have been inconclusive. Although any or anxiogenic effects have been demonstrated in Wistar and Sprague-Dawley rats [83-85], a clear anxiolytic effect was seen in the open field, as well as novelty-induced hypophagia, in BALB/cJ mice [74]. By contrast, in Wistar Kyoto rats, the anxiolytic-like effect after acute administration became a tendency toward an anxiogenic-like effect after chronic administration of fluoxetine [75]. Thus, as mentioned above, the effect of fluoxetine on anxiety-like behaviour also seems to be strain dependent.

\subsection{Effect on cognition}

Cognitive process, including learning and memory, are also events that might be affected by the treatment with fluoxetine. Initial studies demonstrated that fluoxetine improved consolidation and retrieval memory in mice [86], yet subsequently, it was shown that acute administration of fluoxetine $(5$ and $10 \mathrm{mg} / \mathrm{kg}, 24 \mathrm{~h}$ prior to testing) improved the conditioned 
response to a unconditioned stimulus in a dose-dependent manner [87]. However, subsequent studies produced some uncertainty regarding the effect of fluoxetine on memory. On the one hand, chronic administration of low doses of fluoxetine $(0.7 \mathrm{mg} / \mathrm{kg}$ once daily for 28 days $)$ in adult rats did not affect learning and short-term memory, but rather it impaired long-term memory [88]; on the other hand, in adolescent rats subchronic fluoxetine treatment induced cognitive deficits evident in the Morris water maze [89]. These contradictory results could be explained due to different ages tested, and indeed, cognitive deficits have been detected in clinical trials on adolescent patients treated with fluoxetine [90].

Additionally, it is important to note that chronic but not acute administration of fluoxetine increases neurogenesis and improves cognition in adult rodents [64]. The effect of chronic fluoxetine administration on neuroplasticity could explain the underlying antidepressant effects exerted by this compound. Neuroplastic changes require several weeks to be effective, and interestingly, the same time frame was necessary for the recovery of depressed patients after treatment with this antidepressant.

\subsection{Other preclinical studies}

Although most preclinical studies on fluoxetine have focused on depression, 5-HT neurotransmission is also involved in many physiological processes like food intake, aggression, sleep, sexual behaviour, body temperature, fear, vomiting and so on. Thus, the 5-HT reuptake inhibition mediated by fluoxetine is also likely to be effective in animal models of obsessive-compulsive disorder (OCD) [91], panic-like behaviour [92], as well as in bulimia and anorexia nervosa [93]. Indeed, this drug was observed to be effective in pulmonary vascular remodelling induced by methamphetamine [94] and in relieving premenstrual syndrome [95]. However, like other findings with SSRI, fluoxetine had no effect reversing pain-related behaviours [96].

\section{A reflection on the first clinical studies validating the antidepressant effects of fluoxetine}

After numerous preclinical studies demonstrated the efficacy of fluoxetine as a potent antidepressant [71-74,79,81], this compound was tested in patients suffering from depression. In one of the first human studies, the clinical efficacy and safety of fluoxetine was compared with imipramine in a double-blind, 5-week, parallel study performed on 40 depressed out-patients. This study established that fluoxetine is an effective antidepressant with fewer and less troublesome side effects than imipramine [3]. Furthermore, one of the first studies comparing fluoxetine to amitriptyline, another TCA, was carried out in 1985 [97]. In 1985, the efficacy of fluoxetine in OCD was published, a mental status that at that time was treated with chlorimipramine [98]. Up to 1988 , the efficacy and security of fluoxetine had always been compared to that of TCAs, until a review compared the effectiveness of fluoxetine with that of other antidepressants with similar SSRI properties, some of that no longer exist, such as zimelidine [99]. The conclusion was that these compounds were useful to treat not only depression but also anxiety. One of the adverse effects attributed to TCAs are the cardiovascular side effects. In this sense, the safety of fluoxetine was demonstrated in comparison to amitriptyline and many other studies were published in the 1980s on the efficacy and safety of fluoxetine. In function of the dose administered and the treatment time, as well as the type of patient, in these studies fluoxetine emerged as an effective, safe and easy to use antidepressant. Indeed, over the years, it has become the antidepressant of choice in primary care [100], although not all patients reach the desired therapeutic effect being the response rate up to $50 \%$. This percentage could be because depression is a multifactorial disease and changes in genetic, biochemical, neuroanatomic or psychological factors as well as different symptomatology may be responsible for a variation of treatment response pattern among patients.

\section{Conclusion}

In the present review, we briefly describe the development and clinical applications of fluoxetine, one of the first SSRI antidepressants. This compound augments the extracellular levels of 5-HT, accompanied by a decrease in both its synthesis and turnover. Fluoxetine induces several adaptive changes after long-term treatment, including the desensitisation of some 5-HT receptors, and an increase in synaptic plasticity and adult hippocampal neurogenesis. This drug did not show greater affinity for other reuptake transporters (noradrenaline and dopamine), and it has no effect on noradrenergic, histaminergic or cholinergic receptors. The preclinical literature reviewed demonstrates its antidepressant effect in several animal models of depression and anxiety, as well as its effect on cognition.

For years, fluoxetine has been the first-line treatment for depression, a mental disorder that affects $>350$ million people of all ages. Moreover, fluoxetine is also useful for the treatment of other mental disorders, such as anxiety or OCD, in addition to anorexia or bulimia, among others. Finally, fluoxetine is probably the best studied antidepressant in the twentieth century, a period known as 'The Prozac (fluoxetine) era'.

\section{Expert opinion}

For years, the treatment of depression has been a challenge for neuroscientists and psychopharmacologists. The new scientific era of the psychopharmacology of depression commenced when the monoamine hypothesis of depression was postulated, and it was further consolidated through seminal experimental findings and well-designed clinical trials. This also represents the onset of the use of MAOI and TCA antidepressants as 
keystone treatments for depression. However, by 1980, a new and innovative antidepressant had been designed and launched by Lilly, named fluoxetine. It should not be forgotten that the significant advances that have occurred in the development of new antidepressant drugs would not have been possible without the development and validation of new animal models of depression, with predictive validity. However, should bear in mind that animal models of depression widely used are based on the detection of drugs whose mechanism of action consists of increasing monoamine neurotransmission for instance TCA. In this way, it is a limitation for research of new antidepressant compounds due to only the compounds with a positive response in these models will be considered with antidepressant activity. Thus, drugs with potential antidepressant effect mediated by a non-monoaminergic mechanism of action could be discarded. Indeed, fluoxetine as well as other antidepressants may have contributed to stall the development of new models of depression.

Fluoxetine was first erroneously considered the 'moitie' of a TCA. In fact, in contrast to many TCAs, fluoxetine not 'only' inhibits the 5-HT reuptake but also, an added advantage was that fluoxetine does not block histaminergic, cholinergic and $\alpha$-adrenergic receptors. Thus, fluoxetine was devoid of effects on blood pressure and had a better profile of undesirable effects. The success of fluoxetine in clinical setting lead to the hypothesis that tackling serotoninergic neurotransmission was sufficient to produce a satisfactory antidepressant effect avoiding the side effects associated with TCAs. Since this 'discovery', the serotonergic hypothesis of depression became the foremost hypothesis in this field. The logical consequence was that the pharmaceutical industry activated the development of ' $m e$ too' drugs, those similar to fluoxetine. This is not completely true, as some SSRI were studied prior to fluoxetine, although fluoxetine was the first to be recognised as a selective inhibitor of 5-HT reuptake. Nowadays, there are a series of SSRI that are as effective as fluoxetine, with very few pharmacological differences among them.

Fluoxetine is not only an antidepressant but can also reduce the symptomatology of various mental disorders, such as bulimia, anorexia, anxiety, OCDs and many others. 'Prozac', the brand name, was referred to as the 'happy-pill' and indeed, its efficacy and relative safety, and the lack of side effects initially described meant that fluoxetine became the most widely used antidepressant for many years.
Fluoxetine is efficiently absorbed from the gastrointestinal tract after oral administration, and the long half-life contributed to it acceptance. Fluoxetine was, and is, extensively studied in practically all models of mental disorders available in preclinical research, and it has also been studied in other psychiatric conditions in addition to depression.

According to new research and new experimental findings, we now know that fluoxetine is also able to enhance the availability of neurotrophic factors. These effects of fluoxetine led to postulate that depression might be a degenerative process. In fact, neuroimaging studies and neurochemical findings have demonstrated that fluoxetine can aid the recovery from the loss of neurons, even inducing adult neurogenesis. This opens new avenues for the psychopharmacology of fluoxetine, as well as for the development of novel antidepressants with new mechanism of actions, better efficacy and fewer side effects.

\section{Acknowledgments}

The authors thank M Sefton of BIOMEDRED SL. Madrid, Spain, for correcting the English language of this article.

\section{Declaration of interest}

All the authors are supported by CIBERSAM (Centro de Investigación Biomedica en Red de Salud Mental (G18)). E Berrocoso and JA Mico are supported by Cátedra Externa del Dolor Fundación Grünenthal-Universidad de Cádiz. $S$ Torres-Sanchez is also supported by an FPI (2011-145) fellowship. L Perez-Caballero, E Berrocoso, S Torres-Sanchez and JA Mico are all supported by the Health Research Fund (Fondo de Investigación Sanitaria) by grants number PI10/ 01221 and PI13/02659. E Berrocoso, JA Mico and L Bravo are also supported by Health Research fund grant PI12/ 00915. Furthermore, all the authors are supported by Junta de Andalucía grant CTS-510. The Juanta de Andalucia also provided grant CTS-7748 to L Perez-Caballero, E Berrocoso, J A Mico and S Torres-Sanchez and grant CT-4303 to E Berrocoso, L Bravo and J A Mico. The authors have no other relevant affiliations or financial involvement with any organisation or entity with a financial interest in or financial conflict with the subject matter or materials discussed in the manuscript apart from those disclosed. 


\section{Bibliography}

Papers of special note have been highlighted as either of interest $(\bullet)$ or of considerable interest

$(\bullet \bullet)$ to readers.

1. Murray CJ, Lopez AD. Evidence-based health policy-lessons from the Global Burden of Disease Study. Science 1996;1;274(5288):740-3

2. Schildkraut JJ. The catecholamine hypothesis of affective disorders: a review of supporting evidence. Am J Psychiatry 1965;122(5):509-22

3. Bremner JD. Fluoxetine in depressed patients: a comparison with imipramine. J Clin Psychiatry 1984;45(10):414-19

- Relevant clinical trial showing the fewer side effects of fluoxetine compared with imipramine.

4. Robertson DW, Jones ND, Swartzendruber JK, et al. Molecular structure of fluoxetine hydrochloride, a highly selective serotonin-uptake inhibitor. J Med Chem 1988;31(1):185-9

5. Hyttel J. Pharmacological characterization of selective serotonin reuptake inhibitors (SSRIs). Int Clin Psychopharmacol 1994;9(Suppl 1):19-26

6. Wong DT, Bymaster FP, Reid LR, et al. Norfluoxetine enantiomers as inhibitors of serotonin uptake in rat brain. Neuropsychopharmacology 1993;8(4):337-44

-• A broad study about fluoxetine affinities for main neurotransmitter receptors, as well as those by other antidepressants.

7. van Harten J. Clinical pharmacokinetics of selective serotonin reuptake inhibitors. Clin Pharmacokinet 1993;24(3):203-20

8. Bergstrom RF, Lemberger L, Farid NA, Wolen RL. Clinical pharmacology and pharmacokinetics of fluoxetine: a review. Br J Psychiatry 1988(3):47-50

9. Stevens JC, Wrighton SA. Interaction of the enantiomers of fluoxetine and norfluoxetine with human liver cytochromes P450. J Pharmacol Exp Ther 1993;266(2):964-71

10. Lemberger L, Bergstrom RF, Wolen RL, et al. Fluoxetine: clinical pharmacology and physiologic disposition. J Clin Psychiatry 1985;46(3 Pt 2):14-19

11. Wong DT, Horng JS, Bymaster FP, et al. A selective inhibitor of serotonin uptake: lilly 110140 ,

3-(p-trifluoromethylphenoxy)-N-methyl-

3-phenylpropylamine. Life Sci

1974;15(3):471-9

12. Owens MJ, Morgan WN, Plott SJ, Nemeroff CB. Neurotransmitter receptor and transporter binding profile of antidepressants and their metabolites. J Pharmacol Exp Ther 1997;283(3):1305-22

13. Wong DT, Bymaster FP, Horng JS, Molloy BB. A new selective inhibitor for uptake of serotonin into synaptosomes of rat brain: 3-(p-trifluoromethylphenoxy). $\mathrm{N}$-methyl-3-phenylpropylamine. J Pharmacol Exp Ther 1975;193(3):804-11

14. Sanchez C, Hyttel J. Comparison of the effects of antidepressants and their metabolites on reuptake of biogenic amines and on receptor binding. Cell Mol Neurobiol 1999;19(4):467-89

15. Bymaster FP, Zhang W, Carter PA, et al. Fluoxetine, but not other selective serotonin uptake inhibitors, increases norepinephrine and dopamine extracellular levels in prefrontal cortex. Psychopharmacology (Berl) 2002;160(4):353-61

16. Wood MD, Broadhurst AM, Wyllie MG. Examination of the relationship between the uptake system for 5-hydroxytryptamine and the high-affinity $[3 \mathrm{H}]$ imipramine binding site-I. Inhibition by drugs. Neuropharmacology 1986;25(5):519-25

17. Koch S, Perry KW, Nelson DL, et al. R-fluoxetine increases extracellular DA, $\mathrm{NE}$, as well as $5-\mathrm{HT}$ in rat prefrontal cortex and hypothalamus: an in vivo microdialysis and receptor binding study. Neuropsychopharmacology 2002;27(6):949-59

18. Bel N, Artigas F. In vivo effects of the simultaneous blockade of serotonin and norepinephrine transporters on serotonergic function. Microdialysis studies. J Pharmacol Exp Ther 1996;278(3):1064-72

19. Kreiss DS, Lucki I. Effects of acute and repeated administration of antidepressant drugs on extracellular levels of 5-hydroxytryptamine measured in vivo. J Pharmacol Exp Ther 1995;274(2):866-76
20. Rutter JJ, Auerbach SB. Acute uptake inhibition increases extracellular serotonin in the rat forebrain. J Pharmacol Exp Ther 1993;265(3):1319-24

- Microdialysis study that reveals the mechanistic effect of fluoxetine.

21. Sabol KE, Richards JB, Seiden LS. Fluoxetine attenuates the DL-fenfluramine-induced increase in extracellular serotonin as measured by in vivo dialysis. Brain Res 1992;585(1-2):421-4

22. Artigas F. 5-HT and antidepressants: new views from microdialysis studies. Trends Pharmacol Sci 1993;14(7):262

- Short communication that propose the possible role of autoreceptors desensitisation after long-term duloxetine treatment.

23. Malagie I, Trillat AC, Jacquot C, Gardier AM. Effects of acute fluoxetine on extracellular serotonin levels in the raphe: an in vivo microdialysis study. Eur J Pharmacol 1995;286(2):213-17

24. Hervas I, Artigas F. Effect of fluoxetine on extracellular 5-hydroxytryptamine in rat brain. Role of 5-HT autoreceptors. Eur J Pharmacol 1998;358(1):9-18

25. Romero L, Hervas I, Artigas F. The 5-HT1A antagonist WAY-100635 selectively potentiates the presynaptic effects of serotonergic antidepressants in rat brain. Neurosci Lett 1996;219(2):123-6

26. Palvimaki EP, Roth BL, Majasuo H, et al. Interactions of selective serotonin reuptake inhibitors with the serotonin 5-HT2c receptor. Psychopharmacology (Berl) 1996;126(3):234-40

27. Gobert A, Rivet JM, Lejeune F, et al. Serotonin(2C) receptors tonically suppress the activity of mesocortical dopaminergic and adrenergic, but not serotonergic, pathways: a combined dialysis and electrophysiological analysis in the rat. Synapse 2000;36(3):205-21

28. Chen NH, Reith ME. Effects of locally applied cocaine, lidocaine, and various uptake blockers on monoamine transmission in the ventral tegmental area of freely moving rats: a microdialysis study on monoamine interrelationships. J Neurochem 1994;63(5):1701-13

29. Perry KW, Fuller RW. Fluoxetine increases norepinephrine release in rat 
hypothalamus as measured by tissue levels of MHPG-SO4 and microdialysis in conscious rats. J Neural Transm 1997;104(8-9):953-66

30. Ichikawa J, Meltzer HY. Effect of antidepressants on striatal and accumbens extracellular dopamine levels. Eur J Pharmacol 1995;281(3):255-61

31. Perry KW, Fuller RW. Extracellular 5-hydroxytryptamine concentration in rat hypothalamus after administration of fluoxetine plus L-5-hydroxytryptophan. J Pharm Pharmacol 1993;45(8):759-61

32. Invernizzi R, Bramante M, Samanin R. Role of 5-HT1A receptors in the effects of acute chronic fluoxetine on extracellular serotonin in the frontal cortex. Pharmacol Biochem Behav 1996;54(1):143-7

33. Rutter JJ, Gundlah C, Auerbach SB. Increase in extracellular serotonin produced by uptake inhibitors is enhanced after chronic treatment with fluoxetine. Neurosci Lett 1994;171(1-2):183-6

- Relevant study demostrating the increase of serotonine levels after chronic fluoxetine, which is blocked by 5- $\mathrm{HT}_{1 \mathrm{~A}}$ agonist.

34. Amargos-Bosch M, Artigas F, Adell A. Effects of acute olanzapine after sustained fluoxetine on extracellular monoamine levels in the rat medial prefrontal cortex. Eur J Pharmacol 2005;516(3):235-8

35. Tanda G, Frau R, Di Chiara G. Chronic desipramine and fluoxetine differentially affect extracellular dopamine in the rat prefrontal cortex.

Psychopharmacology (Berl)

1996;127(2):83-7

36. Le Poul E, Boni C, Hanoun N, et al. Differential adaptation of brain 5-HT1A and 5-HT1B receptors and 5-HT transporter in rats treated chronically with fluoxetine. Neuropharmacology 2000;39(1):110-22

37. Sharp T, Bramwell SR, Grahame-Smith DG. 5-HT1 agonists reduce 5-hydroxytryptamine release in rat hippocampus in vivo as determined by brain microdialysis. Br J Pharmacol 1989;96(2):283-90

38. Descarries L, Riad M. Effects of the antidepressant fluoxetine on the subcellular localization of 5-HT1A receptors and SERT. Philos Trans R Soc Lond B Biol Sci 2012;5;367(1601):2416-25
39. Hensler JG. Differential regulation of 5-HT1A receptor-G protein interactions in brain following chronic antidepressant administration.

Neuropsychopharmacology 2002;26(5):565-73

40. Wong DT, Reid LR, Bymaster FP, Threlkeld PG. Chronic effects of fluoxetine, a selective inhibitor of serotonin uptake, on neurotransmitter receptors. J Neural Transm 1985;64(3-4):251-69

41. Li Q, Muma NA, van de Kar LD. Chronic fluoxetine induces a gradual desensitization of 5-HT1A receptors: reductions in hypothalamic and midbrain $\mathrm{Gi}$ and $\mathrm{G}(\mathrm{o})$ proteins and in neuroendocrine responses to a 5-HT1A agonist. J Pharmacol Exp Ther 1996;279(2):1035-42

42. Blier P, Chaput $\mathrm{Y}$, de Montigny C. Long-term 5-HT reuptake blockade, but not monoamine oxidase inhibition, decreases the function of terminal 5-HT autoreceptors: an electrophysiological study in the rat brain.

Naunyn Schmiedebergs Arch Pharmacol 1988;337(3):246-54

43. Newman ME, Shalom G, Ran A, et al. Chronic fluoxetine-induced desensitization of 5-HT1A and 5-HT1B autoreceptors: regional differences and effects of WAY-100635. Eur J Pharmacol 2004;486(1):25-30

44. Neumaier JF, Root DC, Hamblin MW. Chronic fluoxetine reduces serotonin transporter mRNA and 5-HT1B mRNA in a sequential manner in the rat dorsal raphe nucleus.

Neuropsychopharmacology 1996;15(5):515-22

45. Gobbi M, Crespi D, Foddi MC, et al. Effects of chronic treatment with fluoxetine and citalopram on 5-HT uptake, 5-HT1B autoreceptors, 5-HT3 and 5-HT4 receptors in rats.

Naunyn Schmiedebergs Arch Pharmacol 1997;356(1):22-8

46. Vidal R, Valdizan EM, Mostany R, et al. Long-term treatment with fluoxetine induces desensitization of 5-HT4 receptor-dependent signalling and functionality in rat brain. J Neurochem 2009;110(3):1120-7

47. Fuxe K, Ogren SO, Agnati LF, et al. Chronic antidepressant treatment and central 5-HT synapses.
Neuropharmacology 1983;22(3 Spec No):389-400

48. Peroutka SJ, Moskowitz MA, Reinhard JF Jr, Snyder SH. Neurotransmitter receptor binding in bovine cerebral microvessels. Science 1980;208(4444):610-12

49. Zhang W, Perry KW, Wong DT, et al. Synergistic effects of olanzapine and other antipsychotic agents in combination with fluoxetine on norepinephrine and dopamine release in rat prefrontal cortex.

Neuropsychopharmacology 2000;23(3):250-62

50. Covington HE III, Vialou VF, LaPlant Q, et al.

Hippocampal-dependent antidepressantlike activity of histone deacetylase inhibition. Neurosci Lett 2011;15;493(3):122-6

51. Baudry A, Mouillet-Richard S, Schneider B, et al. miR-16 targets the serotonin transporter: a new facet for adaptive responses to antidepressants. Science 2010;329(5998):1537-41

52. O'Connor RM, Grenham S, Dinan TG, Cryan JF. microRNAs as novel antidepressant targets: converging effects of ketamine and electroconvulsive shock therapy in the rat hippocampus. Int J Neuropsychopharmacol 2013;16(8):1885-92

53. Oh YS, Gao P, Lee KW, et al. SMARCA3, a chromatin-remodeling factor, is required for p11-dependent antidepressant action. Cell 2013;152(4):831-43

54. Neto FL, Borges G, Torres-Sanchez S, et al. Neurotrophins role in depression neurobiology: a review of basic and clinical evidence. Curr Neuropharmacol 2011;9(4):530-52

55. Coppell AL, Pei Q, Zetterstrom TS. Bi-phasic change in BDNF gene expression following antidepressant drug treatment. Neuropharmacology 2003;44(7):903-10

56. Khundakar AA, Zetterstrom TS. Biphasic change in BDNF gene expression following antidepressant drug treatment explained by differential transcript regulation. Brain Res 2006;1106(1):12-20

57. Sairanen M, Lucas G, Ernfors P, et al. Brain-derived neurotrophic factor and antidepressant drugs have different but 
coordinated effects on neuronal turnover, proliferation, and survival in the adult dentate gyrus. J Neurosci 2005;25(5):1089-94

- Remarkable paper about long-term fluoxetine effects on BDNF, neurogenesis, cell proliferation and survival.

58. Nibuya M, Nestler EJ, Duman RS. Chronic antidepressant administration increases the expression of cAMP response element binding protein (CREB) in rat hippocampus. J Neurosci 1996;16(7):2365-72

59. Song N, Nakagawa S, Izumi $T$, et al. Involvement of CaMKIV in neurogenic effect with chronic fluoxetine treatment. Int J Neuropsychopharmacol 2013;16(4):803-12

60. Mallei A, Shi B, Mocchetti I. Antidepressant treatments induce the expression of basic fibroblast growth factor in cortical and hippocampal neurons. Mol Pharmacol 2002;61(5):1017-24

61. Warner-Schmidt JL, Duman RS. VEGF as a potential target for therapeutic intervention in depression. Curr Opin Pharmacol 2008;8(1):14-19

62. Hajszan T, MacLusky NJ, Leranth C. Short-term treatment with the antidepressant fluoxetine triggers pyramidal dendritic spine synapse formation in rat hippocampus. Eur J Neurosci 2005;21(5):1299-303

63. Varea E, Blasco-Ibanez JM, Gomez-Climent MA, et al. Chronic fluoxetine treatment increases the expression of PSA-NCAM in the medial prefrontal cortex.

Neuropsychopharmacology 2007;32(4):803-12

64. Santarelli L, Saxe M, Gross C, et al. Requirement of hippocampal neurogenesis for the behavioral effects of antidepressants. Science 2003;301(5634):805-9

-• Robust study demonstrating the effect of chronic but not acute administration of fluoxetine on neurogenesis and subsequent behavioural response.

65. McGuirk J, Muscat R, Willner P. Effects of chronically administered fluoxetine and fenfluramine on food intake, body weight and the behavioural satiety sequence. Psychopharmacology (Berl) 1992;106(3):401-7
66. Datla KP, Mitra SK, Bhattacharya SK. Serotonergic modulation of footshock induced aggression in paired rats. Indian J Exp Biol 1991;29(7):631-5

67. Maswood N, Sarkar J, Uphouse L. Modest effects of repeated fluoxetine on estrous cyclicity and sexual behavior in Sprague Dawley female rats. Brain Res 2008;1245:52-60

68. Bravo L, Berrocoso E, Mico JA. Animal models in psychiatry: conceptualization and preclinical models of depression. Eur J Psychiatr 2009;23(Suppl):111-22

69. Nagayama H, Hingtgen JN, Aprison MH. Pre- and postsynaptic serotonergic manipulations in an animal model of depression.

Pharmacol Biochem Behav 1980;13(4):575-9

70. Maj J, Rogoz Z, Skuza G, Sowinska H. The effect of selective inhibitors of noradrenaline and serotonin uptake on reserpine- and apomorphine induced hypothermia in mice. Pol J Pharmacol Pharm 1983;35(1):49-57

71. Gambarana C, Ghiglieri O, Taddei I, et al. Imipramine and fluoxetine prevent the stress-induced escape deficits in rats through a distinct mechanism of action. Behav Pharmacol 1995;6(1):66-73

72. Detke MJ, Rickels M, Lucki I. Active behaviors in the rat forced swimming test differentially produced by serotonergic and noradrenergic antidepressants. Psychopharmacology (Berl) 1995;121(1):66-72

- First study demonstrating that the antidepressant effect of fluoxetine selectively decreased immobility by increasing swimming behaviour in the forced swimming test.

73. Cryan JF, Page ME, Lucki I. Differential behavioral effects of the antidepressants reboxetine, fluoxetine, and moclobemide in a modified forced swim test following chronic treatment.

Psychopharmacology (Berl)

2005;182(3):335-44

74. Dulawa SC, Holick KA, Gundersen B, Hen R. Effects of chronic fluoxetine in animal models of anxiety and depression. Neuropsychopharmacology 2004:29(7):1321-30

75. Griebel G, Cohen C, Perrault G, Sanger DJ. Behavioral effects of acute and chronic fluoxetine in Wistar-Kyoto rats. Physiol Behav 1999;67(3):315-20
76. Trivedi MH, Rush AJ, Armitage R, et al. Effects of fluoxetine on the polysomnogram in outpatients with major depression.

Neuropsychopharmacology 1999;20(5):447-59

77. Monti JM, Jantos H. A study of the brain structures involved in the acute effects of fluoxetine on REM sleep in the rat. Int J Neuropsychopharmacol 2005;8(1):75-86

78. Ivarsson M, Paterson LM, Hutson PH. Antidepressants and REM sleep in Wistar-Kyoto and Sprague-Dawley rats. Eur J Pharmacol 2005;522(1-3):63-71

79. Grippo AJ, Beltz TG, Weiss RM, Johnson AK. The effects of chronic fluoxetine treatment on chronic mild stress-induced cardiovascular changes and anhedonia. Biol Psychiatry 2006;59(4):309-16

80. Song C, Leonard BE. The olfactory bulbectomised rat as a model of depression. Neurosci Biobehav Rev 2005;29(4-5):627-47

81. Machado DG, Cunha MP, Neis VB, et al. Fluoxetine reverses depressive-like behaviors and increases hippocampal acetylcholinesterase activity induced by olfactory bulbectomy.

Pharmacol Biochem Behav 2012;103(2):220-9

- Original paper that revealed chronic fluoxetine reversed olfactory bulbectomy-induced depressivelike behaviour.

82. Roche M, Harkin A, Kelly JP. Chronic fluoxetine treatment attenuates stressor-induced changes in temperature, heart rate, and neuronal activation in the olfactory bulbectomized rat. Neuropsychopharmacology 2007:32(6):1312-20

83. Robert G, Drapier D, Bentue-Ferrer D, et al. Acute and chronic anxiogenic-like response to fluoxetine in rats in the elevated plus-maze: modulation by stressful handling. Behav Brain Res 2011;220(2):344-8

84. Silva RC, Brandao ML. Acute and chronic effects of gepirone and fluoxetine in rats tested in the elevated plus-maze: an ethological analysis.

Pharmacol Biochem Behav 2000;65(2):209-16

85. Iniguez $\mathrm{SD}$, Warren $\mathrm{BL}$, Bolanos-Guzman CA. Short- and longterm functional consequences of 
fluoxetine exposure during adolescence in male rats. Biol Psychiatry

2010;67(11):1057-66

86. Flood JF, Cherkin A. Fluoxetine enhances memory processing in mice. Psychopharmacology (Berl) 1987;93(1):36-43

87. Meneses A, Hong E. Effect of fluoxetine on learning and memory involves multiple 5-HT systems.

Pharmacol Biochem Behav 1995;52(2):341-6

88. Ampuero E, Stehberg J, Gonzalez D, et al. Repetitive fluoxetine treatment affects long-term memories but not learning. Behav Brain Res 2013;247:92-100

89. Sass A, Wortwein G. The effect of subchronic fluoxetine treatment on learning and memory in adolescent rats. Behav Brain Res 2012;228(1):169-75

90. Bangs ME, Petti TA, Janus MD. Fluoxetine-induced memory impairment in an adolescent. J Am Acad Child Adolesc Psychiatry 1994;33(9):1303-6

91. Altemus M, Glowa JR, Galliven E, et al. Effects of serotonergic agents on food-restriction-induced hyperactivity. Pharmacol Biochem Behav 1996;53(1):123-31

92. Poltronieri SC, Zangrossi H Jr, de Barros Viana M. Antipanic-like effect of serotonin reuptake inhibitors in the elevated T-maze. Behav Brain Res 2003;147(1-2):185-92
93. Lauzurica N, Garcia-Garcia L, Fuentes JA, Delgado M. Hypophagia and induction of serotonin transporter gene expression in raphe nuclei of male and female rats after short-term fluoxetine treatment. J Physiol Biochem 2013;69(1):69-74

94. Liu M, Wang Y, Wang HM, et al. Fluoxetine attenuates chronic methamphetamine-induced pulmonary arterial remodelling: possible involvement of serotonin transporter and serotonin $1 \mathrm{~B}$ receptor. Basic Clin Pharmacol Toxicol 2013;112(2):77-82

95. Ho HP, Olsson M, Westberg L, et al. The serotonin reuptake inhibitor fluoxetine reduces sex steroid-related aggression in female rats: an animal model of premenstrual irritability? Neuropsychopharmacology 2001;24(5):502-10

96. Mico JA, Ardid D, Berrocoso E, Eschalier A. Antidepressants and pain. Trends Pharmacol Sci 2006;27(7):348-54

97. Chouinard G. A double-blind controlled clinical trial of fluoxetine and amitriptyline in the treatment of outpatients with major depressive disorder. J Clin Psychiatry 1985;46(3 Pt 2):32-7

-. A double-blind controlled clinical trial that investigated the efficacy and safety of fluoxetine.

98. Turner SM, Jacob RG, Beidel DC, Himmelhoch J. Fluoxetine treatment of obsessive-compulsive disorder.
J Clin Psychopharmacol 1985;5(4):207-12

99. Burrows GD, McIntyre IM, Judd FK, Norman TR. Clinical effects of serotonin reuptake inhibitors in the treatment of depressive illness. J Clin Psychiatry 1988;49(Suppl):18-22

100. Simon GE, VonKorff M, Heiligenstein JH, et al. Initial antidepressant choice in primary care. Effectiveness and cost of fluoxetine vs tricyclic antidepressants. JAMA 1996;275(24):1897-902

\section{Affiliation}

Laura Perez-Caballero ${ }^{1,2}$, Sonia Torres-Sanchez ${ }^{1,2}$, Lidia Bravo ${ }^{1,2} \mathrm{PhD}$, Juan Antonio Mico ${ }^{1,2} \mathrm{MD} \mathrm{PhD} \&$ Esther Berrocoso ${ }^{\dagger 2,3} \mathrm{PhD}$

${ }^{\dagger}$ Author for correspondence

${ }^{1}$ University of Cadiz, Department of

Neuroscience, Neuropsychopharmacology and Psychobiology Research Group, Cádiz 11003, Spain

${ }^{2} \mathrm{PhD}$ student,

Instituto de Salud Carlos III, Centro de Investigación Biomédica en Red de Salud Mental (CIBERSAM), Madrid, 28007, Spain

${ }^{3}$ University of Cadiz, Department of Psychology, Neuropsychopharmacology and Psychobiology Research Group, Psychobiology Area, Campus Universitario Rio San Pedro s/n, Puerto Real (Cadiz) 11510, Spain

Tel: +34 956015224;

Fax: +34 956015225;

E-mail: esther.berrocoso@uca.es 